Research Article

\title{
Numerical Simulation of Coupling Thermal and Mechanical Influence on Submerged Nozzle in Solid Rocket Motor
}

\author{
Jian-Liang Gong \\ Xi'an Modern Chemistry Research Institute, Xi'an 710065, China \\ Correspondence should be addressed to Jian-Liang Gong; 271373251@qq.com
}

Received 15 February 2020; Accepted 12 May 2020; Published 30 September 2020

Academic Editor: Desong Fan

Copyright (c) 2020 Jian-Liang Gong. This is an open access article distributed under the Creative Commons Attribution License, which permits unrestricted use, distribution, and reproduction in any medium, provided the original work is properly cited.

\begin{abstract}
The coupling thermal and mechanical effect on submerged nozzles is important in the design of modern rockets upon thermal loading and aerodynamic pressure. In this paper, a simulation with the subroutine of nonuniform pressure and nonuniform heat transfer coefficient was conducted to study the thermo-structural response of a submerged nozzle at the pressure $6 \mathrm{MPa}$ and stagnation temperature $3200 \mathrm{~K}$. Both the aerodynamic parameters and heat coefficients were obtained through analyzing the flow field. It was found that the thermal loading had an important influence on the stress of throat insert for the solid rocket motor (SRM). The hoop stress increases at first and then decreases with the increase of time for the throat insert. The ground hot firing test of SRM with a submerged nozzle was carried out. The experimental results showed that the structural integrity of the submerged nozzle is very normal during SRM operation. The present method is reasonable, which can be applied to study the thermo-structural response of submerged nozzle for SRM.
\end{abstract}

\section{Introduction}

The SRM nozzle always acts as the energy transformation equipment where the chemical energy of the propellant turns into the kinetic energy of gas [1]. In order to shorten the length of a solid rocket motor, the submerged nozzle is adopted in high altitude solid rocket motor [2,3]. It is classified as a submerged nozzle, as its entrance extends to within the combustion chamber of the SRM. In general, the submerged nozzle is always working under extremely harsh circumstances, such as thermal load, mechanical load, thermochemical ablation, and particle-laded flow [4-7]. Hence, the structure integrity is of great importance for the normal operation of the nozzle. Hence, the simulation of the submerged nozzle is carried out to analyze the structure integrity, such as flow simulation, heat transfer simulation, and structure analysis [8].

A variety of recent works account for the growth in knowledge and techniques in the assessment of the structural behavior of SRM nozzles. Kumar et al. [9] undertook an extensive thermo-structural analysis of composite structures, incorporating temperature-dependent properties, and ther- mal, thermo-chemical and mechanical loads, and subsequently performed a coupled thermo-structural stress analysis of an SRM nozzle comprised of various orthotropic and isotropic materials. Morozov and Beaujardiere [10] investigated the dynamic thermo-structural response of a composite rocket nozzle throat using the commercial finite element code ADINA. It is found that the dynamic response oscillates about the quasi-static response in all cases, and that, in general, the variance in stress magnitudes between the two solution techniques is significant. Tian et al. [11] studied the problems with gap design and contact stress about the SRM nozzle under thermal loading and pressure using the finite element method. Li et al. [12] had a focus on the thermal structural analysis of the nozzle throat insert; the influences of the thermoelastic stress are discussed by the computational software ABAQUS. Zheng [13] studied the thermostructural analysis and failure behaviors of carbon-carbon composite throat insert. Hu et al. [14] determined the temperature and stress field of the conical trapped joint carbon-carbon nozzle divergent section. Sun et al. [15] studied the thermo-structural response of a typical nozzle with consideration of the structure gap based on the finite element 


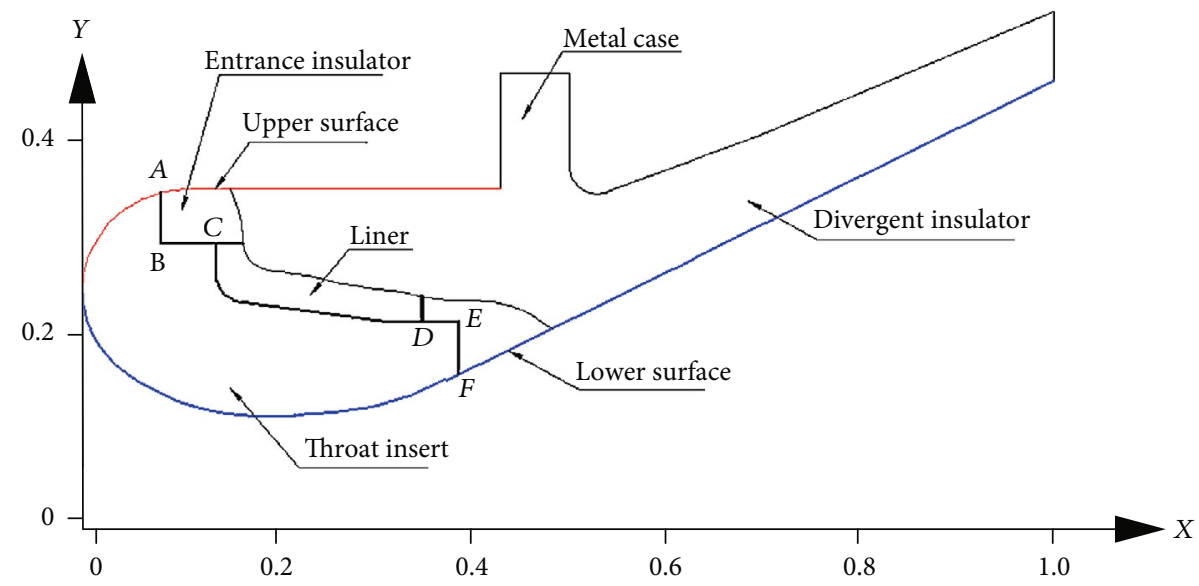

Figure 1: Model of submerged nozzle.

method.YU et al. [16] considered the influence of the fit clearance of the throat insert on the deformation and stress distribution of the nozzle based on the three-dimensional finite element model. The research shows that the fit clearance of throat insert does not change the overall distribution of stress, but can affect the stress on the matching surface. Cozart and Shivakumar [17] performed a finite element axisymmetric stress analysis of a 3-D braided preform ablative composite rocket nozzle, incorporating a material ablation model. In the work of Yoo et al. [18], a kick motor nozzle utilizing spatially reinforced composites was subjected to finite element thermo-elastic analyses following the development of a material model used to homogenize various spatial reinforcement architectures.

To sum up, a large amount of work has been done for investigating the thermo-structural response. However, literature on the thermo-structural response of the submerged nozzle at the initial stages of operation is scarce. This study focuses on the numerical simulation of the submerged nozzle under the condition of internal pressure and thermal loading. It addresses a method for analyzing the thermo-structural response of nozzle using a finite element analysis program and discusses the development of a user subroutine which allows us to model the nonuniform pressure and nonuniform heat transfer coefficients on the wall. Furthermore, the ground hot firing test of SRM is carried out. Finally, some conclusions are drawn in the end.

\section{Submerged Nozzle Model}

2.1. Geometry. The three-dimensional cyclic symmetry finite element analysis is performed for the submerged nozzle made of different composites. This nozzle consists of five substructures, namely, throat insert made from the punctured carbon-carbon composite, the tape wound 2D silica-phenolic entrance insulator-which isolates the hot gas and metal case, the silica-phenolic liner-which isolates the hot and cooler substructures, divergent insulator made from the silica-phenolic, and metal case made from the titanium alloy, as shown in Figure 1. In Figure 1, the coordinate of $X$-axis is dimensionless by the nozzle length. Furthermore, in order to reduce the thermal stress of the throat insert, the clearance was set up in the
TABLE 1: Material properties of titanium alloy.

\begin{tabular}{cccccc}
\hline$\rho$ & $\lambda$ & $\alpha$ & $C_{p}$ & $E$ & $\mu$ \\
\hline 4500 & 7.955 & $7.89 \mathrm{E}-6$ & 725.7 & $1.1 \mathrm{E} 6$ & 0.34 \\
\hline
\end{tabular}

internal interface of the throat insert. The values of interface $\mathrm{AB}, \mathrm{BC}, \mathrm{DE}$, and $\mathrm{EF}$ are all 0.05 millimeters.

2.2. Assumptions. Some reasonable assumptions are considered as follows to simplify the geometry model:

(1) The outer surface of the nozzle has no heat exchange

(2) The pure gas steady gas is considered, the flow field is steady

(3) The contact thermal resistance is totally ignored for the simulation

(4) The complicated phenomena of erosion and pyrolysis behavior of the erosion and heat insulation materials are neglected

(5) The radiation heat transfer is not considered

2.3. Material Properties. There are three kinds of materials for the submerged nozzle, which are titanium alloy, silica-phenolic, and carbon-carbon composite. Silica-phenolic and carboncarbon materials are treated as homogeneous and orthotropic, and their properties are related to temperature. The properties of titanium alloy, silica-phenolic, and carbon-carbon materials are shown in Tables $1-3$, where $T$ represents temperature $(K)$, $\lambda$ represents thermal conductivity $\left(\mathrm{W} . \mathrm{m}^{-1} \cdot \mathrm{K}^{-1}\right), C_{p}$ represents specific heat $\left(\mathrm{W} \cdot \mathrm{kg}^{-1} \cdot \mathrm{K}^{-1}\right), \alpha$ represents the coefficient of thermal expansion $\left(\mathrm{K}^{-1}\right), E$ represents Young's modulus ( $\left.\mathrm{MPa}\right), G$ represents shear modulus $(\mathrm{MPa}), \mu$ represents Poisson's ratio, and $\rho$ represents the density $\left(\mathrm{kg} / \mathrm{m}^{3}\right)$.

2.4. Mesh. A properly sized mesh can generate more accurate results and reduce the computing resources for the thermostructural simulation. A $1 / 12$ th $3 \mathrm{D}$ symmetric model is used in this paper for the simulation. The cylindrical coordinate system is adopted to impose symmetric constraints on the 
TABle 2: Material properties of silica-phenolic composite.

\begin{tabular}{lcccccccccccc}
\hline$T$ & $\rho$ & $\lambda_{11}$ & $\lambda_{22} / \lambda_{33}$ & $\alpha_{11}$ & $\alpha_{22} / \alpha_{33}$ & $C_{p}$ & $E_{11}$ & $E_{22} / E_{33}$ & $G_{23}$ & $G_{12} / \mathrm{G}_{13}$ & $\mu_{23}$ & $\mu_{13} / \mu_{12}$ \\
\hline 300 & & 0.61 & 0.52 & $6.0 \mathrm{E}-6$ & $6.0 \mathrm{E}-6$ & $1.0 \mathrm{E} 3$ & $1.2 \mathrm{E} 4$ & $8.2 \mathrm{E} 3$ & $5.1 \mathrm{e} 3$ & $2.1 \mathrm{e} 3$ & \\
500 & & 0.72 & 0.71 & & & & & & & & \\
800 & 1650 & 0.86 & 0.85 & & & & & & & \\
1100 & & 1.3 & 1.1 & $8.0 \mathrm{E}-6$ & $8.0 \mathrm{E}-6$ & $1.2 \mathrm{E} 3$ & $8.1 \mathrm{E} 3$ & $6.3 \mathrm{E} 3$ & $3.1 \mathrm{e} 3$ & 800 & \\
\hline
\end{tabular}

TABLE 3: Material properties of carbon-carbon composite.

\begin{tabular}{|c|c|c|c|c|c|c|c|c|c|c|c|c|}
\hline$T$ & $\rho$ & $\lambda_{11}$ & $\lambda_{22} / \lambda_{33}$ & $\alpha_{11}$ & $\alpha_{22} / \alpha_{33}$ & $C_{p}$ & $E_{11}$ & $E_{22} / E_{33}$ & $G_{23}$ & $G_{12} / G_{13}$ & $\mu_{23}$ & $\mu_{13} / \mu_{12}$ \\
\hline 300 & \multirow{8}{*}{1890} & 65.8 & 86.5 & \multirow{5}{*}{$1.3 \mathrm{E}-6$} & \multirow{5}{*}{$1.2 \mathrm{E}-6$} & 920 & & & & & & \\
\hline 500 & & 60.6 & 84.2 & & & 1001 & & & & & & \\
\hline 800 & & 59.5 & 81.2 & & & 1279 & & & & & & \\
\hline 1100 & & 55.1 & 71.2 & & & 1487 & 452 & 64853 & 22553 & 20652 & 202 & 0.1 \\
\hline 1400 & & \multirow{4}{*}{51.3} & \multirow{4}{*}{62.5} & & & 1567 & $42.5 \mathrm{EJ}$ & $04.8 \mathrm{E}$ & ZL.JEJ & 20.0EJ & 0.22 & 0.11 \\
\hline 1700 & & & & \multirow{3}{*}{$1.4 \mathrm{E}-6$} & \multirow{3}{*}{$1.3 \mathrm{E}-6$} & & & & & & & \\
\hline 2000 & & & & & & 1785 & & & & & & \\
\hline 2300 & & & & & & & & & & & & \\
\hline
\end{tabular}

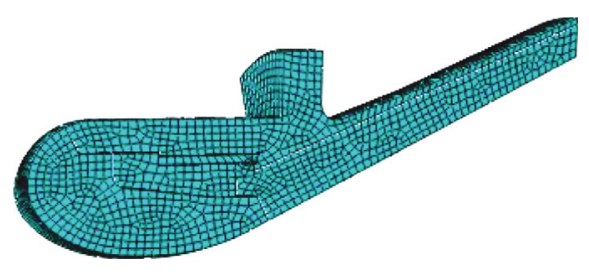

Figure 2: Mesh generation.

symmetric surface. Figure 2 shows the mesh generation result of the thermo-structural simulation. This model is also used to simulate the nonlinear and orthotropic material properties. The finite element model is generated by a structured grid. There are 9453 elements in the finite element mesh. Figure 2 shows the mesh generation result.

2.5. Boundary Conditions. The simulation for the submerged nozzle is subjected to both thermal and mechanical excitations during the period of analysis. To solve the problem of thermal-structure, both the fluid software and structure software are employed. The first stage entails the aerodynamics of flow on the surface of the nozzle. The second stage supplies the temperature and stress distribution for structure. The flow diagram of the simulation is presented in Figure 3.

On the one hand, in order to obtain the steady flow filed, the axisymmetric numerical simulation was carried out by a finite volume method, based on a pressure solver. A standard $\kappa-\varepsilon$ model was used to make the gas phase equation as a closed system. On the other hand, there exist two kinds of thermal boundary conditions for structure simulation, i.e., the adiabatic condition between the outermost structural steel and the air, and the forced convection from the inner flow. For thermal-structural simulation, the heat transfer coefficient along the wall should be provided by means of fluid software. The result is shown in Figures 4-6, respectively. Figure 4 shows the temperature distribution, gradually decreasing

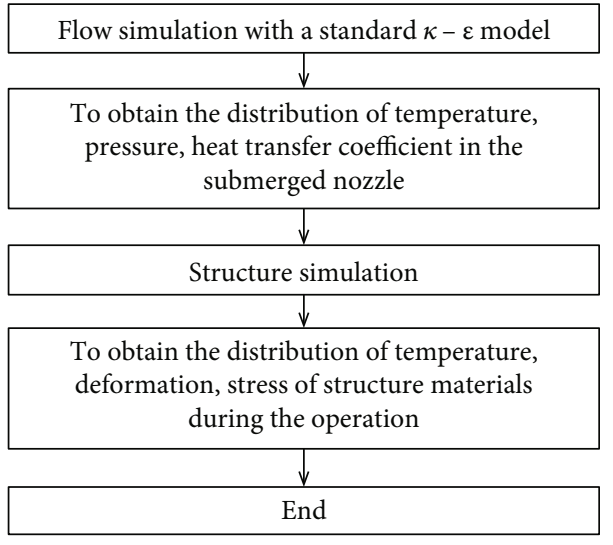

Figure 3: Flow diagram of simulation.

along the wall. Figure 5 shows the force convective coefficient between hot gas and wall. As can be seen, the maximum value of the forced convection coefficient is about $8266 \mathrm{~W} /\left(\mathrm{m}^{2} \cdot \mathrm{K}\right)$, and the minimum value is about $324 \mathrm{~W} /\left(\mathrm{m}^{2} \cdot \mathrm{K}\right)$. It is noticed that the variation curve of the heat transfer coefficient presents a peak at the upstream of the throat insert. Figure 6 shows the pressure distribution, gradually decreasing along the wall, because of the gas exhaust flow.

\section{Results and Discussion}

3.1. Thermal Loading. For the submerged nozzle, the distribution of temperature was obtained at times $28 \mathrm{~s}$ based on the finite element method on the conditions of thermal loading, as shown in Figure 7. The stagnation temperature is $3200 \mathrm{~K}$. The transient thermal analysis is run to get the temperature profile of the nozzle at the end of 28 seconds. It indicates that the convection heat transfer between the gas and the throat insert is very obvious, and the temperature of this 


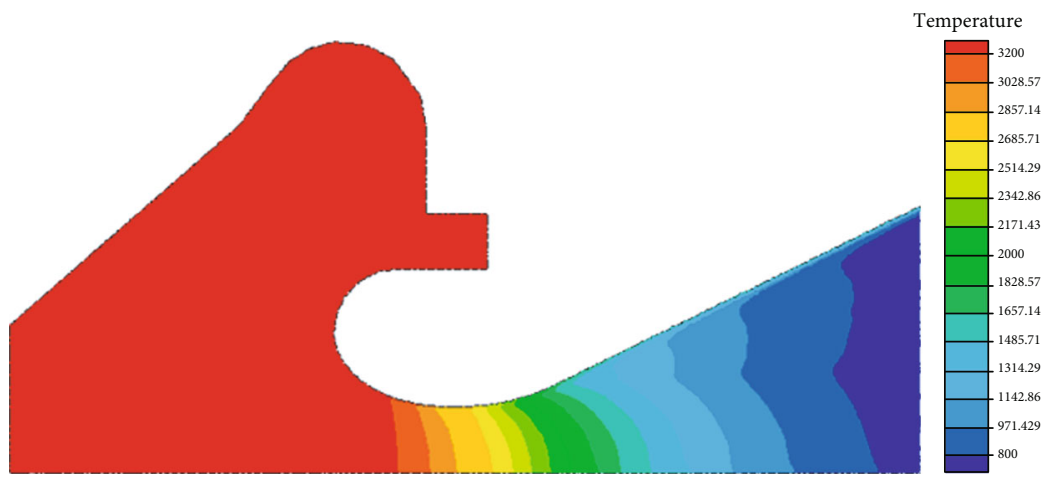

FIgURE 4: Temperature distribution about the steady field of SRM, K.

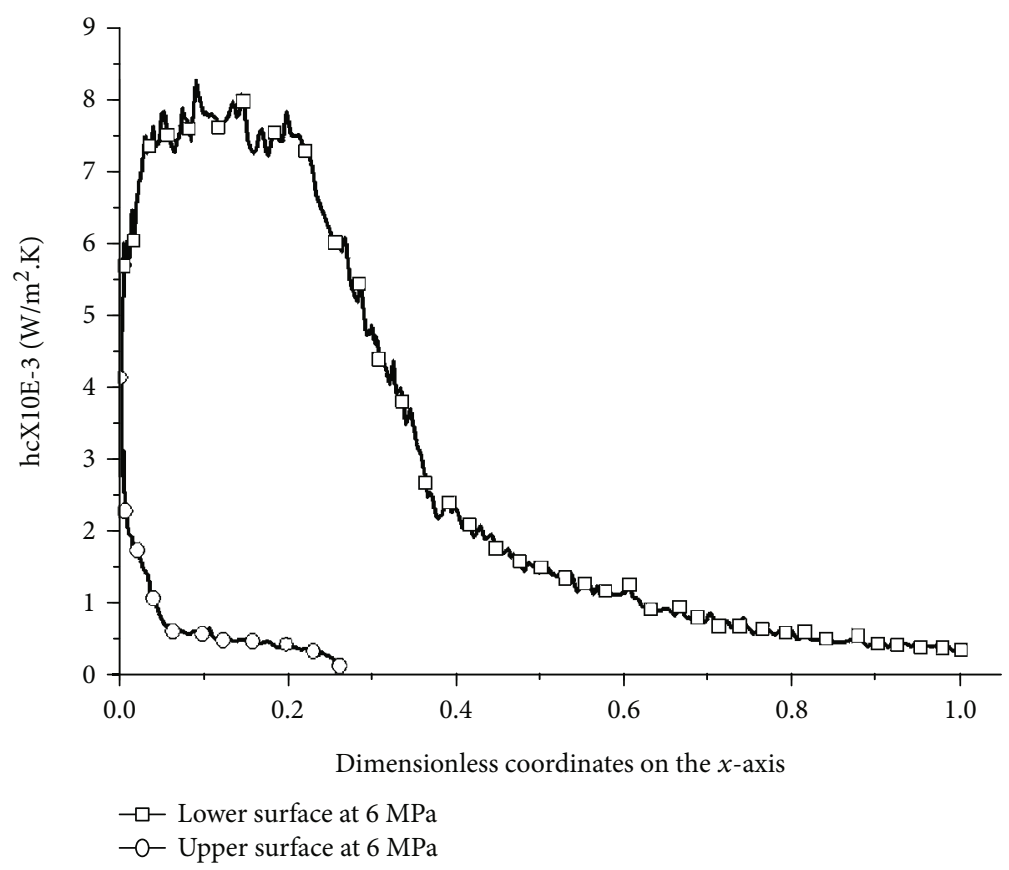

Figure 5: Heat transfer coefficient of the inner surface in Figure 1.

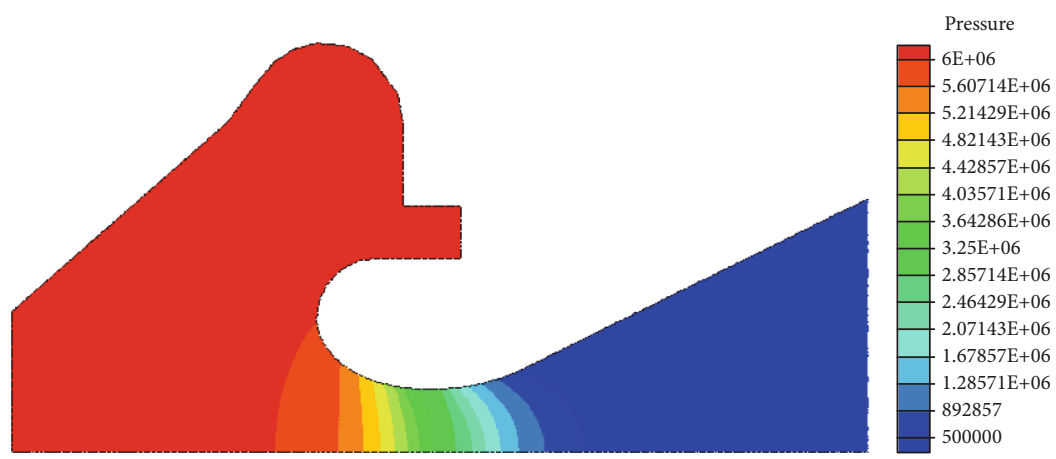

FIGURE 6: Pressure distribution about the steady field of SRM, Pa.

material increases greatly. Because the conductivity of the carbon-carbon composite is high, and the heat transfer coefficient is large as shown in Figure 5. Secondly, the outer surface of the case is low, which is $300 \mathrm{~K}$ environmental temperature, because the conductivity of the liner is much lower than that of the throat insert. This plays an important role in the insulation of the case. Finally, the heat transfer depth of the entrance insulator and the divergent insulator is shallow, because these convective coefficients are low as shown in Figure 5. 


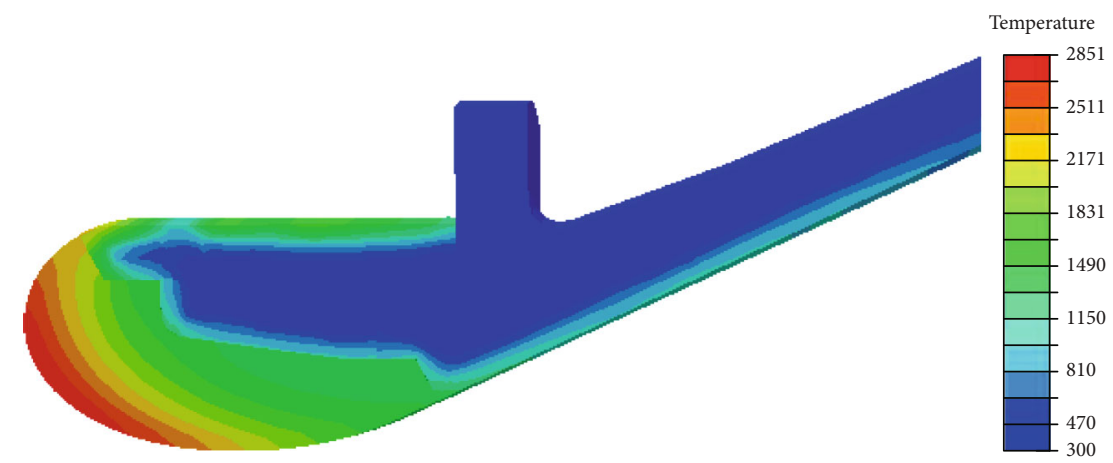

FIgURE 7: Temperature distribution under the thermal loading at time $28 \mathrm{~s}, \mathrm{~K}$.

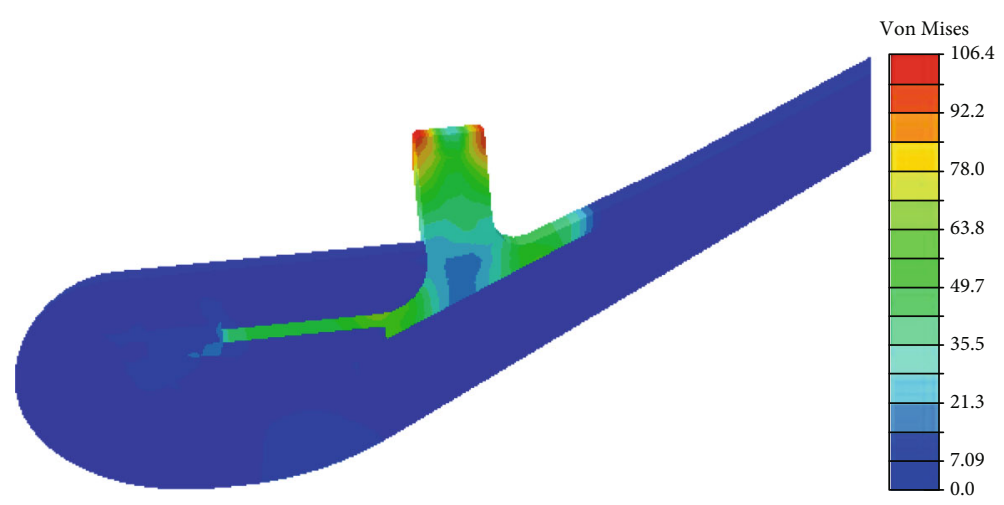

FIgURe 8: Von Mises stress distribution under the pressure at time $28 \mathrm{~s}, \mathrm{MPa}$.

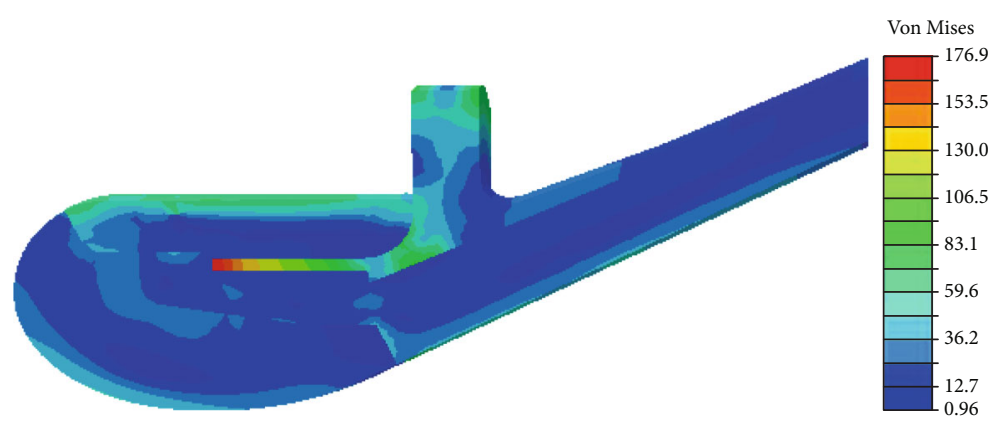

Figure 9: Von Mises stress distribution of submerged nozzle at $28 \mathrm{~s}$ under thermal loading and pressure, MPa.

3.2. Mechanical Loading. For the submerged nozzle, the distribution of Von Mises stress was obtained at $28 \mathrm{~s}$ based on the same method on the condition of pressure, as shown in Figure 8 . The stagnation of temperature and pressure is $3200 \mathrm{~K}$ and $6 \mathrm{MPa}$, respectively. It can be seen that the position of the maximum Von Mises stress is the outer surface of the case, and the value is about $176 \mathrm{MPa}$. Secondly, the stress of the protective materials for the nozzle is small under the pressure, and the maximum of Von Mises stress for the throat insert is only $12 \mathrm{MPa}$.

\subsection{Both Thermal and Mechanical Loading}

3.3.1. Discussion about Strength. On the condition of the thermal loading and pressure, the distribution of Von Mises stress was obtained at time $28 \mathrm{~s}$ for the submerged nozzle, as shown in Figure 9. The stagnation of temperature and pressure is $3200 \mathrm{~K}$ and $6 \mathrm{MPa}$, respectively. It is interesting to note that the position of the maximum Von Mises stress is the front end of the cylindrical section of the case, and the maximum value is $176 \mathrm{MPa}$. Compared with the Figure 8, the maximum Von Mises stress increased obviously, the thermal expansion of the thermal protective materials is caused by the rise of the internal temperature. The contact interface of these materials is compressed from each other due to the inconsistency of the expansion deformation. It is shown that the thermal expansion of the protective materials has an important influence on the stress of the case.

The throat insert is the one subjected to the most severe thermal and mechanical loading, which provides an appropriate case for study. Furthermore, the hoop stress is the most important stress component. Figure 10 displays the hoop 


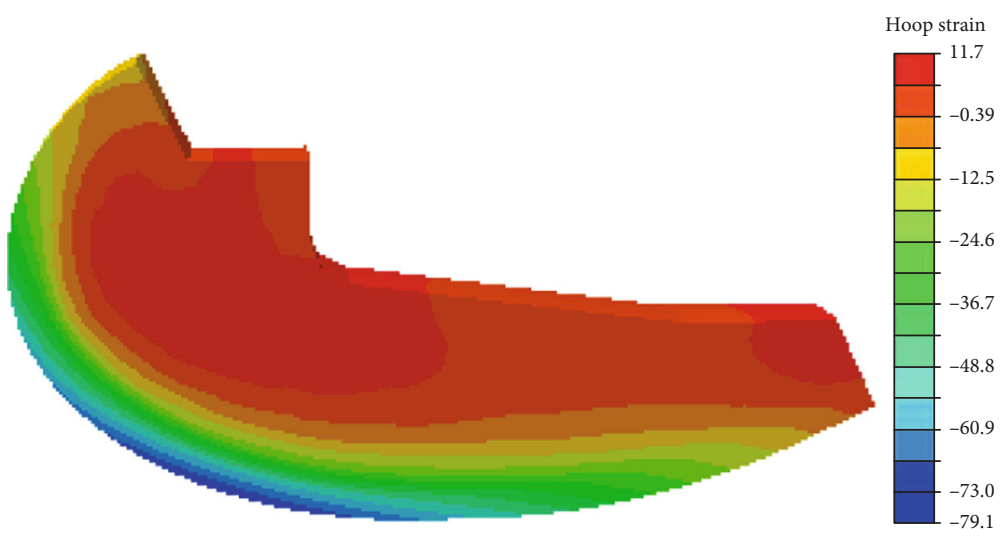

(a)

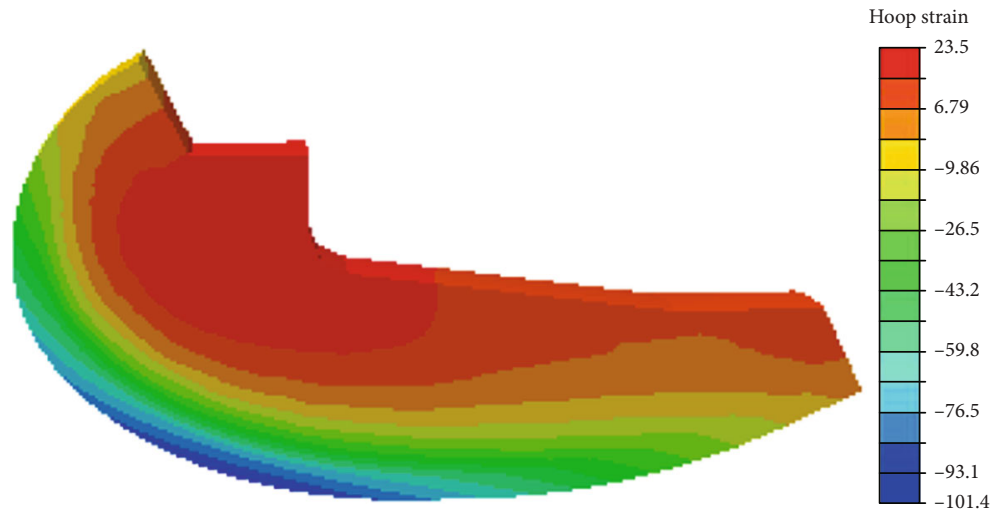

(b)

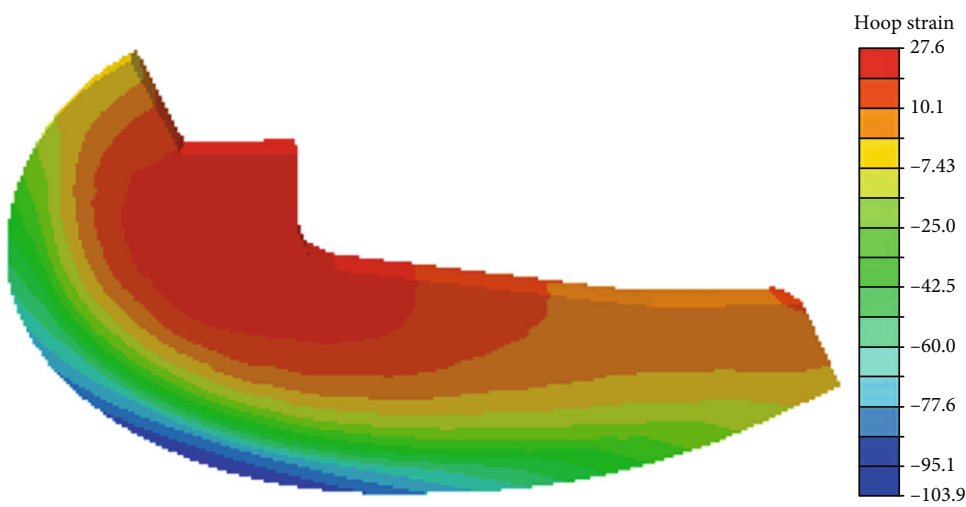

(c)

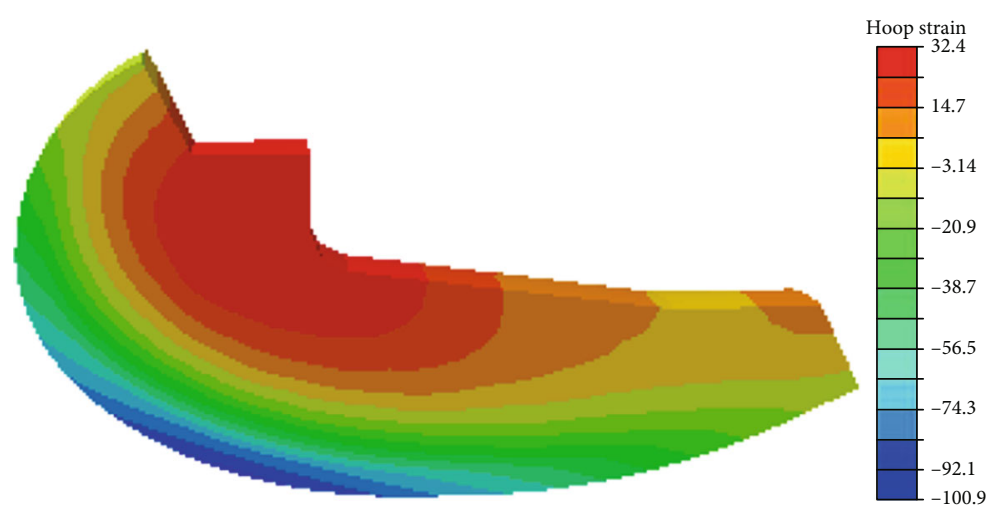

(d)

Figure 10: Continued. 


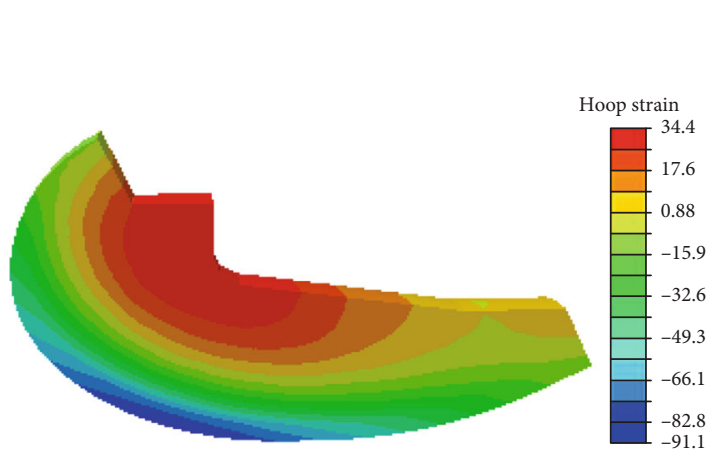

(e)

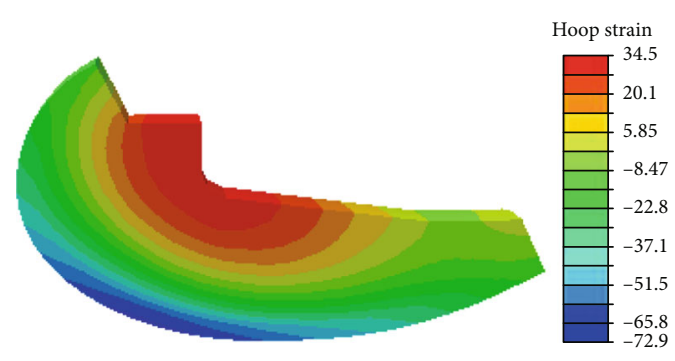

(g)

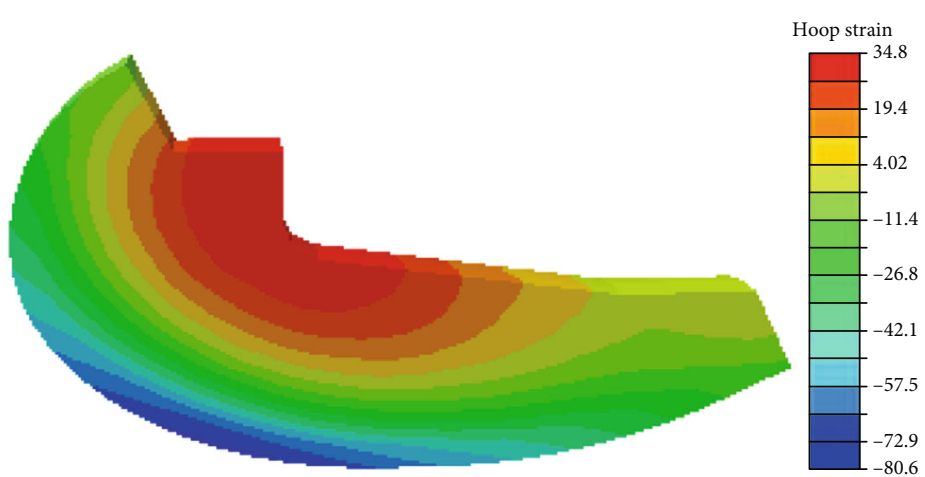

(f)

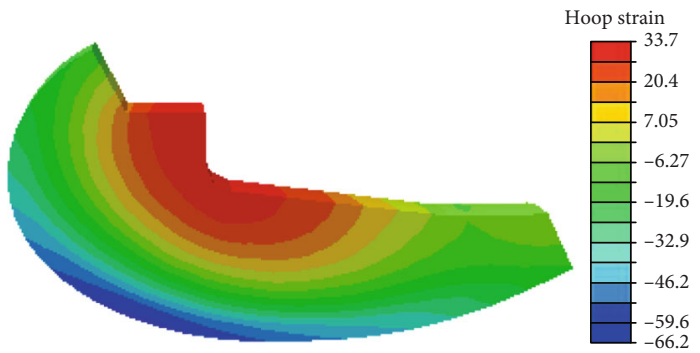

(h)

Figure 10: Hoop stress of throat insert at different times: (a) at $1.3 \mathrm{~s}$, (b) at $4.1 \mathrm{~s},(\mathrm{c})$ at $6.1 \mathrm{~s},(\mathrm{~d})$ at $10.1 \mathrm{~s},(\mathrm{e})$ at $15.1 \mathrm{~s},(\mathrm{f})$ at $20.1 \mathrm{~s},(\mathrm{~g})$ at 24.1 , (h) at $28.0 \mathrm{~s}, \mathrm{MPa}$.

stress of the throat insert at different times. It is clear that the position of the maximum hoop compressive stress is upstream at the convergent section of the throat insert, because of the maximum heat transfer coefficient in the upstream of throat insert, the temperature difference is large, and the thermal expansion deformation of throat insert is obvious. Secondly, the position of the maximum hoop tensile stress is at the inner fillet of the throat insert. In order to avoid the damage of throat insert during the test, the radius of the inner fillet can be properly increased. Thirdly, the hoop stress increases at first and then decreases with time for the throat insert. Finally, during the working operation, the maximum hoop compressive stress of throat insert is $6.1 \mathrm{~s}$, and its value is 103.9 MPa, which is less than $180 \mathrm{MPa}$ of compress strength. The maximum hoop stress $34.8 \mathrm{MPa}$ of throat insert is $20.1 \mathrm{~s}$, and its value is 34.8 MPa, which is less than $115 \mathrm{MPa}$ of tensile strength. Both maximum hoop compressive stress and maximum tensile stress yield the material strength.

The contact stress of forward and backward interface in the throat insert has an important influence on the stress distribution and the safety of nozzle during the operation. In particular, both forward gap $\mathrm{AB}$ and backward gap EF are very important in Figure 1. Therefore, the value of forward gap $A B$ in Figure 1 is 0.05 millimeters, and the one of backward value EF is 0.05 millimeters. Figure 11 shows the distribution of contact stress for the throat insert at time 28 seconds. It indicates that the value of contact stress is larger at the front face $\mathrm{AB}$, and the value of contact stress is smaller at the back face EF. This is the reason that the gas temperature at upstream is much higher than the one at downstream for throat insert. In order to ensure the reliability of the

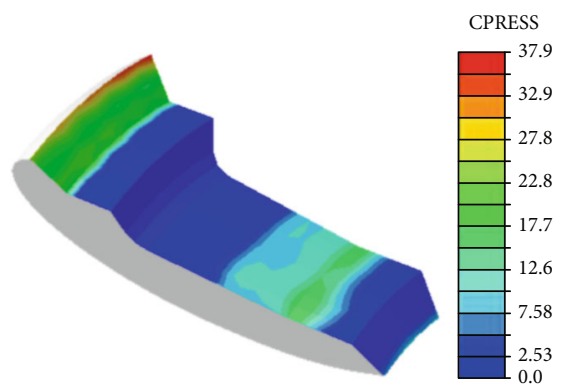

FIGURE 11: Distribution of contact stress for throat insert at $28 \mathrm{~s}$, MPa.

throat insert, the interface gap of the front face of the throat insert can be properly increased, and the interface gap of the back face can be reduced.

3.4. Experimental Verification of Structural Integrity for the Throat Insert. On the condition of combustion chamber pressure $6 \mathrm{MPa}$ and stagnation temperature $3200 \mathrm{~K}$, the ground hot firing test of SRM with the submerged nozzle was carried out, and the working time was $28 \mathrm{~s}$. In addition, the design values of interface $\mathrm{AB}, \mathrm{BC}, \mathrm{DE}$, and $\mathrm{EF}$, as shown in Figure 1, are all 0.05 millimeters. The structural integrity of the submerged nozzle is normal. Figure 12 shows the structure of the throat insert after the test of the submerged nozzle. During the SRM operation, the performance of the submerged nozzle yields the requirement of SRM. Meanwhile, the test value of hoop strain for a metal case is $1258 \mu \varepsilon$ at time $28 \mathrm{~s}$, and the computational value is $1164 \mu \varepsilon$, as shown in Figure 13, Point A. It can be seen that the computational value 


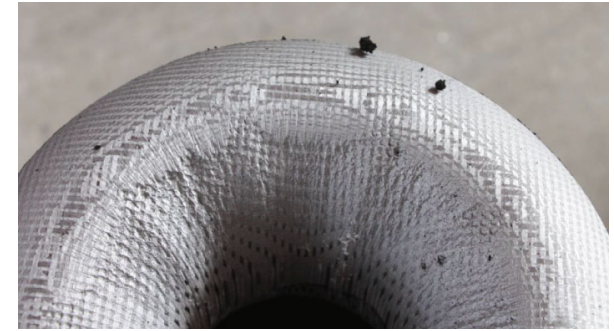

FIGURE 12: Throat insert after the ground hot firing test.

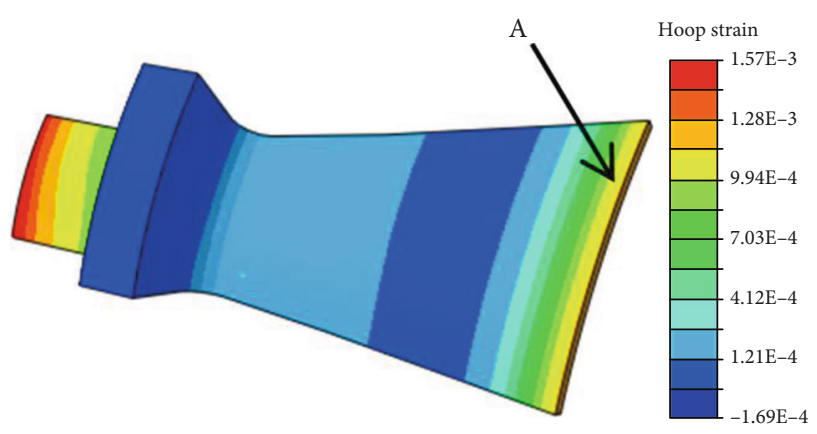

FIGURE 13: Hoop strain distribution of metal case with simulation.

is equivalent to the test value. Furthermore, it can be shown that the method of thermo-structure response of submerged nozzle developed in this paper is reasonable. The structure design and interface clearance of throat insert is valid. The distribution of stress field and temperature field for the throat insert are sound, which yields meet the material strength.

\section{Conclusion}

In this paper, the thermo-structure response of threedimensional submerged nozzle under the condition of thermal loading and pressure was investigated. The ground firing test of SRM has been completed. Some conclusions can be drawn as follows:

(1) Thermal loading is found to have the most dominating influence on the thermal stress of nozzle

(2) The hoop stress of throat insert increases at first and then decreases with the increase of time

(3) In order to ensure the reliability of the submerged nozzle, the design of throat insert clearance and structure is extremely important

\section{Data Availability}

As most of the data in this manuscript were related to trade secrets, I cannot provide them completely. In the future, if necessary, I can share some data with the reviewers or readers.

\section{Conflicts of Interest}

The authors declare that they have no conflicts of interest.

\section{Acknowledgments}

This article was funded by Xi'an Modern Chemistry Research Institute, China.

\section{References}

[1] P. F. Melia, "Flow and ablation patterns in Titan IV SRM aft closures," in 31st Joint Propulsion Conference and Exhibit, p. 2878, San Diego, CA, USA, 1995.

[2] E. R. Joyce and M. P. Snyder, "Solid rocket motor design for a high altitude composite rocket," in 45th AIAA/ASME/SAE/ASEE Joint Propulsion Conference \& Exhibit, p. 5083, Denver, CO, USA, 2009.

[3] M. Angelone, F. Mascanzoni, and C. Milana, "Technological and programmatic development of Zefiro 40 solid rocket motor," in 48th AIAA/ASME/SAE/ASEE Joint Propulsion Conference \& Exhibit, p. 4213, Atlanta, GA, USA, 2012.

[4] B. C. Yang, A Theoretical Study of Thermo-Mechanical Erosion of High-Temperature Ablatives, The Pennsylvania State University, University Park, State College, PA, USA, 1992.

[5] Y. W. Guan, J. Li, and Y. Liu, "Ablation characteristics and reaction mechanism of insulation materials under slag deposition condition," Acta Astronautica, vol. 136, no. 4, pp. 80-89, 2017.

[6] J. Li, M. F. Guo, X. Lv, Y. Liu, K. Xi, and Y. W. Guan, "Erosion characteristics of ethylene propylene diene monomer composite insulation by high-temperature dense particles," Acta Astronautica, vol. 145, no. 2, pp. 293-303, 2018.

[7] Y. Liu, Y. W. Guan, and J. Li, "Insulator ablation modes in different impact conditions of alumina droplets onto wall surfaces," Acta Astronautica, vol. 153, no. 6, pp. 138-145, 2018.

[8] Q. Li, P. J. Liu, and G. Q. He, "Fluid-solid coupled simulation of the ignition transient of solid rocket motor," Acta Astronautica, vol. 110, no. 3, pp. 180-190, 2015.

[9] R. R. Kumar, G. Vinod, S. Renjith, G. Rajeev, M. K. Jana, and R. Harikrishnan, "Thermo-structural analysis of composite structures," Materials Science and Engineering A, vol. 412, no. 1-2, pp. 66-70, 2005.

[10] E. V. Morozov and J. Beaujardiere, "Numerical simulation of the dynamic thermostructural response of a composite rocket nozzle throat," Composite Structures, vol. 91, no. 4, pp. 412420, 2009.

[11] S. P. Tian, G. J. Tang, D. K. Li, and D. C. Yuan, "Gap design of solid rocket motor nozzle structures," Journal of Propulsion Technology, vol. 26, no. 5, pp. 448-451, 2005.

[12] S. L. Li, F. Zhang, and B. Xiong, "Influences factor analysis of thermal structure on motor throat," Structure and Environment Engineering, vol. 40, no. 2, pp. 56-63, 2013.

[13] Q. Zheng, Thermo-Structural Analysis and Failure Behavior of C/C Composite Throat, Harbin Institute of Technology, Harbin, China, 2011.

[14] J. H. Hu, S. H. Meng, X. L. Chang, C. H. Xu, and H. Chen, "Temperature and stress field analysis of conical trapped joint C/C nozzle divergent section," Journal of Solid Rocket Technology, vol. 35, no. 1, pp. 64-68, 2012.

[15] L. Sun, F. T. Bao, N. Zhang et al., "Thermo-Structural Response Caused by Structure Gap and Gap Design for Solid Rocket Motor Nozzles," Energies, vol. 9, no. 6, p. 430,2016 . 
[16] X. J. Yu, S. Yu, Y. Wang, and Y. Yang, "Thermo-structure coupled computation for the influence of fit clearance on the stress distribution of composite nozzle," in 2018 Joint Propulsion Conference, p. 4486, Cincinnati, OH, USA, 2018.

[17] A. B. Cozart and K. N. Shivakumar, "Stress analyses of a 3-D braided composite ablative nozzle," in 40th Structures, Structural Dynamics, and Materials Conference and Exhibit, p. 1277, St. Louis, MO, USA, 1999.

[18] J. S. Yoo, I. H. Cho, and C. G. Kim, "Thermoelastic analysis of a kick motor nozzle incorporating spatially reinforced composites," Journal of Spacecraft and Rockets, vol. 40, no. 1, pp. 83-91, 2003. 